ఠ

\title{
Potential underdiagnosis of osteoporosis in repeated vertebral augmentation for new vertebral compression fractures
}

This article was published in the following Dove Press journal:

Clinical Interventions in Aging

14 September 2015

Number of times this article has been viewed

\author{
Birkan İlhan \\ Fatih Tufan \\ Gülistan Bahat \\ Mehmet Akif Karan \\ Division of Geriatrics, Department \\ of Internal Medicine, Istanbul \\ Medical School, Istanbul University, \\ Istanbul, Turkey
}

Correspondence: Birkan İlhan Division of Geriatrics, Department of Internal Medicine, Istanbul Medical School, Istanbul University, PB 34093 Sehremini Istanbul Turkiye

Email birkanilhan@hotmail.com

\section{Dear editor}

We read with great interest the article by Liang et al "Repeated vertebral augmentation for new vertebral compression fractures of postvertebral augmentation patients: a nationwide cohort study". ${ }^{1}$

In their study, the authors investigated the factors possibly associated with new vertebral compression fractures in patients who previously had vertebral augmentation procedures. They reported that osteoporosis (OP) was not observed as a risk factor for repeat vertebral augmentation. Among multiple chronic diseases, hypertension (HT) was reported as one factor associated with new vertebral fractures. Among the medications used to treat or prevent OP, they reported calcium/vitamin D, bisphosphonates, and calcitonin were associated with not having repeat vertebral augmentation. However, steroids, paracetamol, and nonsteroidal anti-inflammatory drugs were associated with having repeat vertebral augmentation. We would like to comment on their article.

The authors described OP as a bone mineral density (BMD) of 2.5 standard deviations below the mean peak bone mass as measured by dual-energy X-ray absorptiometry. However, the National Osteoporosis Foundation reported the diagnosis of OP as low BMD measurements or the occurrence of adulthood hip or vertebral fracture in the absence of major trauma. ${ }^{2}$ Vertebral compression fractures would be the only indicator of OP in patients with normal BMD scores. This might have led to underdiagnosis of OP. Furthermore, both vertebral degenerative changes and fractures may cause misinterpretation of BMD scores as normal when there is significant OP. We suggest that using "low BMD score" would be better than "OP" as nonassociated with new vertebral compression fracture. In line with our comments, Table 2 shows that 34,500 patients have a diagnosis of OP; however, as indicated in Table 3, 57,568 patients are undergoing treatment for OP. This inconsistency could mean that the rate of OP is more than determined in this study. It may also mean that multiple OP medications were used concomitantly by some of the patients. This point should be clarified.

The authors reported that the HT and diabetes mellitus were associated with repeat vertebral augmentation. However, it is not discussed how HT may be related to repeat vertebral augmentation. In the elderly, one of the important factors underlying falls may be overtreatment of HT leading to hypotension and/or orthostatic hypotension and consequent falls. ${ }^{3,4}$ Consideration of patients with low blood pressure levels or clinically significant orthostatism on antihypertensive medications would help the authors to interpret this association. 
Another factor that would be associated with having repeat vertebral augmentation is "falls" which could not be estimated in this study database. It would be useful to search "vertigo" or "syncope" as a predisposing risk factor for falling. 5

Although it is rarely diagnosed on clinical grounds, sarcopenia is prevalent in elderly people (between $3 \%$ and $52 \%){ }^{6}$ Sarcopenia is commonly seen in patients with dementia, cerebrovascular accidents, and diabetes, and is a strong risk factor for both OP and falls. ${ }^{2,7}$ We suggest that sarcopenia which is not included in the discussion, should be considered as an important factor underlying the increased risk of vertebral augmentation in these patients.

Finally, regarding the association between the use of analgesics and repeat vertebral augmentation, the authors discussed that the increase in fracture risk in these patients may stem from changes in postural balance or dizziness (a side effect of nonsteroidal anti-inflammatory drugs). In this regard, dizziness is not a known adverse event associated with paracetamol. Therefore, we suggest that there may be an indirect association between analgesics, in particular paracetamol, and repeat vertebral augmentation: patients having more severe fractures and more severe pain might have used these agents more frequently. It is also possible that subjects having pain more commonly visited their physician and pain could be a common indication for repeat vertebral augmentation procedures.

We suggest that the findings of the present study should be interpreted in view of aforementioned considerations.

\section{Disclosure}

The authors have no conflicts of interest to disclose.

\section{References}

1. Liang CL, Wang HK, Syu FK, Wang KW, Lu K, Liliang PC. Repeated vertebral augmentation for new vertebral compression fractures of postvertebral augmentation patients: a nationwide cohort study. Clin Interv Aging. 2015;10:635-642.

2. National Osteoporosis Foundation. Clinician's guide to prevention and treatment of osteoporosis. National Osteoporosis Foundation; 2014. Available from: http://nof.org/files/nof/public/content/file/2791/ upload/919.pdf. Accessed August 12, 2015.

3. Denker MG, Cohen DL. What is an appropriate blood pressure goal for the elderly: review of recent studies and practical recommendations. Clin Interv Aging. 2013;8:1505-1517.

4. Shaw BH, Claydon VE. The relationship between orthostatic hypotension and falling in older adults. Clin Auton Res. 2014;24(1):3-13.

5. Boelens C, Hekman EE, Verkerke GJ. Risk factors for falls of older citizens. Technol Health Care. 2013;21(5):521-533.

6. Volpato S, Bianchi L, Cherubini A, et al. Prevalence and clinical correlates of sarcopenia in community-dwelling older people: application of the EWGSOP definition and diagnostic algorithm. J Gerontol A Biol Sci Med Sci. 2014;69(4):438-446.

7. Landi F, Liperoti R, Russo A, et al. Sarcopenia as a risk factor for falls in elderly individuals: results from the ilSIRENTE study. Clin Nutr. 2012; 31(5):652-658 


\section{Authors' reply \\ Cheng-Loong Liang' \\ Hao-Kwan Wang' \\ Fei-Kai Syu ${ }^{2}$ \\ Kuo-Wei Wang' \\ Kang Lu' \\ Po-Chou Liliang'}

'Department of Neurosurgery, E-Da Hospital, I-Shou University, Kaohsiung City, Taiwan; ${ }^{2}$ Department of Pharmacy, China Medical University Hospital, Taichung City, Taiwan

Correspondence: Po-Chou Liliang

Department of Neurosurgery, E-Da Hospital, I-Shou University,

I Yi-Da Road, Yan-Chau Shiang, Kaohsiung City 824, Taiwan

Tel +86676150011

Fax +86676150982

Email ed100172@edah.org.tw

\section{Dear editor}

We thank İlhan et al for their interest and comments regarding our article. ${ }^{1}$ World Health Organization (WHO) defined osteoporosis as a bone mineral density (BMD) of 2.5 standard deviations or more below the mean peak bone mass (average of young, healthy adults) as measured by dual-energy X-ray absorptiometry. ${ }^{2}$ Many physicians in Taiwan use WHO's definition for the diagnosis of osteoporosis in the study period. Osteoporosis is likely to have been underestimated in our population-based database using this definition. In clinical practice, we found multiple vertebral fractures may have falsely elevated the BMD scores in osteoporotic patients, and osteoporosis could be underestimated when using low BMD scores. ${ }^{3}$ Sometimes vertebral compression fractures would be the only indicator of osteoporosis in patients with normal BMD scores. Recently, the National Osteoporosis Foundation reported the diagnosis of osteoporosis as low BMD measurements or the occurrence of adulthood hip or vertebral fracture in the absence of major trauma ${ }^{4}$ Low BMD measurements with fragility fractures in spine or hips should be considered osteoporosis. The use of low BMD scores is a good idea; however, the difficulty is the exact BMD scores of each patient were not included in the data. If we use the International Classification of Diseases, Ninth Revision, Clinical Modification diagnosis code 733.90 for osteopenia (low BMD T scores between -1 and -2.5 ) perhaps include some patients without true osteoporosis.

The patients undergoing osteoporosis treatment are more than patients with a diagnosis of osteoporosis. It is suggested that physicians would prescribe anti-osteoporotic drugs for some patients with relatively normal BMD scores.

We observed that diabetes mellitus, hypertension, and hyperlipidemia (main components of metabolic syndrome) were significant risk factors associated with repeat vertebral augmentation. ${ }^{1}$ One possible explanation is propensity for falls. The metabolic syndrome is a potential risk factor for falls in older adults and should be addressed with regard to prevention of falls. ${ }^{5}$

Falls is a potential risk factor for vertebral compression fractures. Trivial falls could not be estimated in this study database. We agree that it would be useful to search vertigo, dizziness, or syncope as a predisposing risk factor for falls. These valuable opinions could be helpful for future studies.

\section{Disclosure}

The authors have no conflicts of interest to disclose.

\section{References}

1. Liang CL, Wang HK, Syu FK, Wang KW, Lu K, Liliang PC. Repeated vertebral augmentation for new vertebral compression fractures of postvertebral augmentation patients: a nationwide cohort study. Clin Interv Aging. 2015;10:635-642.

2. World Health Organization. WHO Scientific Group on the Prevention and Management of Osteoporosis at primary health care level. Geneva: World Health Organization; 2004. Available from: http://www.who.int/ chp/topics/Osteoporosis.pdf. Accessed August 12, 2015.

3. Ryan PJ, Evans P, Blake GM, Fogeman I. The effect of vertebral collapse on spinal bone mineral density measurements in osteoporosis. Bone Miner. 1992;18(3):267-272.

4. National Osteoporosis Foundation. Clinician's guide to prevention and treatment of osteoporosis. National Osteoporosis Foundation; 2014. Available from: http://nof.org/files/nof/public/content/file/2791/ upload/919.pdf. Accessed August 12, 2015.

5. Liao KC, Pu SJ, Lin CH, Chang HJ, Chen YJ, Liu MS. Association between the metabolic syndrome and its components with falls in communitydwelling older adults. Metab Syndr Relat Disord. 2012;10:447-451.

Dove Medical Press encourages responsible, free and frank academic debate. The content of the Clinical Interventions in Aging 'letters to the editor' section does not necessarily represent the views of Dove Medical Press, its officers, agents, employees, related entities or the Clinical Interventions in Aging editors. While all reasonable steps have been taken to confirm the content of each letter, Dove Medical Press accepts no liability in respect of the content of any letter, nor is it responsible for the content and accuracy of any letter to the editor.

Clinical Interventions in Aging

Dovepress

\section{Publish your work in this journal}

Clinical Interventions in Aging is an international, peer-reviewed journal focusing on evidence-based reports on the value or lack thereof of treatments intended to prevent or delay the onset of maladaptive correlates of aging in human beings. This journal is indexed on PubMed Central, MedLine,
CAS, Scopus and the Elsevier Bibliographic databases. The manuscript management system is completely online and includes a very quick and fair peer-review system, which is all easy to use. Visit http://www.dovepress. com/testimonials.php to read real quotes from published authors. 